Essay

\title{
Analyzing the Impact of COVID-19 on Education Professionals. Toward a Paradigm Shift: ICT and Neuroeducation as a Binomial of Action
}

\author{
Luis Espino-Díaz * (D), Gemma Fernandez-Caminero, Carmen-Maria Hernandez-Lloret,

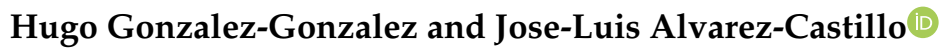

Faculty of Education Sciences, University of Cordoba, 14071 Córdoba, Spain; gemma.fernandez@uco.es (G.F.-C.); m32hellc@uco.es (C.-M.H.-L.); hugo.gonzalez@uco.es (H.G.-G.); jlalvarez@uco.es (J.-L.A.-C.)

* Correspondence: luis.espino@uco.es

Received: 3 June 2020; Accepted: 13 July 2020; Published: 14 July 2020

check for updates

\begin{abstract}
This study analyzed the current situation of education in the context of the pandemic caused by COVID-19. The worldwide health emergency situation has caused the confinement of people and with it, the closure of centers and the transfer of face-to-face education to online education. Faced with these facts, teachers have had to adapt at a dizzying pace not only to new methodological approaches, but also to their own confinement, presenting high levels of stress. The purpose of this study is to offer a proposal that optimizes the work of education professionals in the current context of a pandemic through the use of Information and Communication Technologies (ICT) under the novel approach of the contributions of neuroeducation in the field of managing emotions and motivational processes, contributing to meaningful learning in students. The symbiosis of ICT and neuroeducation can make a great contribution to the paradigm shift that is taking place today.
\end{abstract}

Keywords: COVID-19; stress; teachers; ICT; neuroeducation

\section{Introduction}

The current context under the threat of the pandemic as a result of COVID-19 is causing a series of transformations in the different spheres of social, political, labor, and economic life. Different governments have launched emergency policy initiatives based on the suspension of classes and the closure of educational centers to continue teaching activities from homes telematically through the use of information and communication technologies to be able to stop the number of infections [1]. This study focused on the consequences of the pandemic in the field of education. Specifically, in the paradigm shift that is assuming the transfer from face-to-face teaching to online teaching and how education professionals must face adaptation to the new global context through the online modality, a movement that has occurred and is occurring in a frantic and abrupt way. Consequently, education professionals are carrying out a process of assimilation toward new circumstances with a few difficulties, causing situations of high levels of stress. A survey of more than 10,000 teachers [2] revealed that $92.8 \%$ of teachers suffered emotional exhaustion, stress, anguish, or anxiety due to confinement and distance education. Excessive bureaucratic tasks, unclear instructions, lack of support in teleworking, and lack of technical means were the main problems pointed out by teachers. Possible difficulties facing such policies include poor online teaching infrastructure, lack of teacher training, information gap, and complex home environment. To address the specific problem of teacher training, this analysis suggests teacher training through a series of training guidelines [1].

This analysis is based on the significant deficit in digital competence and knowledge of the use of ICT by education professionals. This question becomes a crucial issue in the current context of 
school closings and the necessary adaptation of online teaching. Different empirical studies have reported the improved knowledge of teachers' digital competence. In this sense, there are studies that report an alarming difference between the competencies that teachers should have to develop digital competence in their students and the ones they truly have [3]. This study has confirmed the existence of an important gap in the teacher training in the use of ICT and its application in the classroom.

Other studies have revealed that teachers carry out continuous training throughout the academic year and demonstrate skills in certain areas of digital teaching competence such as security and communication, although there is still a deficit in the creation of digital content [4].

Another factor to consider is the teacher's self-perception of the need for training in the use of new technologies. On this matter, a previous study [5] reported that $50.0 \%$ perceived a medium need and $37.0 \%$ a high need. Furthermore, the study showed that respondents who reported low competence regarding digitization of teaching reported a statistically significantly higher need for training.

A recent study on digital competence in future teachers that proposes a model for the development of teacher digital competence based on the sociocultural approach [6] revealed a medium level of development of digital competence and concluded that there was still much to do in terms of teacher training in ICT, being necessary to provide strategies for the development of this skill in their students.

The new educational panorama requires the taking of a series of measures, among which the training needs of education professionals to facilitate the assimilation of the current context in which online teaching and the use of ICTs stands out. The present study has a dual purpose: to manifest the needs of training in the educational use of the ICTs of education professionals and, on the other hand, to optimize the use of ICTs through the contributions made by neurosciences, and more specifically from neuroeducation.

One novel approach includes the contributions of neuroeducation, a discipline that offers the keys to understanding how the brain learns in order to apply them effective way in teaching.

The answer lies in knowing what neuroeducation is as a discipline that promotes integration between educational sciences and neurology, where educators and neuroscientists develop disciplines such as psychology, neuroscience, education, and cognitive science. In this way, the teacher must have not only a solid training in their field of knowledge, but also basic knowledge in neuroscience to produce an improvement in teaching methods and in different educational programs.

To carry out this project, first, the current context of educational centers caused by the pandemic situation will be analyzed, specifically, the closure of educational centers and, as a consequence, the change from face-to-face teaching to online teaching through ICT. Subsequently, different measures related to the necessary training of education professionals in this new context will be analyzed. Finally, a work approach is proposed based on the contributions made by neuroeducation as a means of optimizing and channeling the teaching and learning process in this new context.

Regarding the design and methodology of this research, first, a bibliographic search was undertaken to know the current context derived from the pandemic and its derivations in the educational field, highlighting the transfer of traditional teaching to online teaching as well as the training need of teachers in the use of ICT. A proposal for the use of ICT was made from a neuroeducational approach based on previous studies that point in that direction. Through an inductive methodology, a series of conclusions based on different investigations and techniques such as observation, demonstration, and experimentation were drawn up, which were reviewed in the previous bibliography. On the other hand, from an analytical-synthetic perspective, the information obtained both from the current health context, from the use of ICT by teachers and from the contributions of neuroeducation to be related to each other, were analyzed individually to elaborate a global synthesis that leads to connecting the different axes of the investigation and to obtain a series of conclusions that link the use of ICT and neuroeducation. 


\section{Analysis of the Current Educational Context during the Pandemic Caused by COVID-19}

On 11 March 2020, the World Health Organization (WHO) declared that the infection caused by the coronavirus COVID-19 had ceased to be an epidemic and had passed to the category of pandemic. As of 12 May 2020, according to data from the COVID-19 Dashboard by the Center for Systems Science and Engineering (CSSE) at Johns Hopkins University (JHU), more than 4.3 million cases of the disease in more than 212 countries with more than 292,000 deaths and more than 1.6 million cases of people recovered [7]. By continent, as of 13 May 2020, Europe with 1,675,742 affected and 155,762 deaths and North America with 1,544,436 affected and 93,190 deaths are the continents with the highest figures followed by Asia with 701,532 infected and 22,851 deaths, and South America with 335,624 affected and 18,108 deaths [8].

One of the first decisions that the various governments made was to close educational centers. A decision was made based on the indications of previous investigations [9] for pandemic situations, and they concluded that the closure of educational centers together with the implementation of measures such as the isolation of the sick or suspected ill in hospitals or residences, the ban on public gatherings, and the closure of roads and rail lines were effective measures to slow the advance of a pandemic. The report concluded that in the event of a pandemic, decision-making about non-pharmaceutical interventions should be taken into account to implement the use of vaccines, drugs, and prophylactic treatments, although only as a last resort and only for extremely lethal infections, given the high damage to society. In addition, it is the circumstance that COVID-19 is transmitted more easily among the child population than among adults and faster [10]. This behavior of the virus in childhood reaffirms the decision to close schools. Along the same lines, another study by McMaster University analyzed the consequences of the closure of schools for the treatment of a 2009 flu epidemic in a region of Canada and concluded that this measure reduced contagion by $50 \%$ [11].

According to United Nations Educational, Scientific, and Cultural Organization (UNESCO) data as of 3 May 2020, almost 1.2 billion students and youth around the world were affected by the closure of schools and universities due to the outbreak of COVID-19 [12], representing 70\% of this social segment worldwide. This same body has analyzed the consequences of the closure of schools and has established a series of arguments as to why it is a phenomenon of maximum urgency. Among the consequences for children of confinement are the psychological effects, social isolation, difficulties in accessing nutrition, and lack of physical exercise.

\section{Consequences of Closing Schools during the Pandemic}

The consequences of the closure of educational centers has affected the entire population suffering from this situation caused by the pandemic situation, but even more so in the most disadvantaged countries. According to UNESCO [12], there are a number of factors that are seriously affected:

- Disruption of learning: Since the closure of schools implies a deprivation of the right to education and to their own personal development. The more access to education is limited, the greater the damage caused by the closure of educational centers.

- Food: As there are a large number of children and young people who only have the food they receive in schools for free or at a minimal cost.

- Poor training of parents for distance learning: This circumstance is due to the low educational level of the parents, so that once again, the most disadvantaged families are harmed to a greater extent.

- Unequal access to information and communication technologies: The lack of resources, once again, increases the digital divide, which leads to a difficult obstacle to overcome to access learning from digital platforms.

- Lack of childcare: As a result of parents having to leave the house to seek the livelihood of the family, the children are left alone in the houses, and with it, a series of very negative consequences arise. 
- Economic consequences and increased unemployment: Parents with young children have to stay at home to care for their children, which causes a loss of wages and damages the productivity of the region.

- The previous situation is further aggravated when it comes to health personnel who must leave their job, which is very necessary in a pandemic situation.

- After prolonged closure of schools, the possibility of the dropping out of students who do not return after the closure order is completed increases.

Other international reports are positioned along the same line. This is the case of the Organization of Ibero-American States for Education, Science, and Culture (OEI), which focuses on the consequences of the closure of centers at the higher education level in three blocks [13]. First, the effects on student learning. From this aspect, there have been investigations [14] showing that the $10 \%$ reduction in the duration of educational instruction decreases by $1.5 \%$ of the standard deviation, although more recent studies have affirmed that with the use of Information and Communication Technologies (ICT) under an appropriate approach, learning should not be impaired or diminished by the interruption of face-to-face classes [15]. In fact, a meta-analysis was commissioned by the United States Department of Education [16], in which virtual learning was compared to face-to-face learning. The analysis was very conclusive and reported that the mean effect was a $24 \%$ higher standard deviation for virtual learning. Second, the effects on future student wages. Regarding this consequence, the decrease in salary stands out in those students who suffered a closure of their training centers and consequently saw their level of learning decrease with the corresponding downward labor remuneration [17]. Finally, the effects on the educational dropout rate. As already mentioned, the closure of schools may result in an increase in dropout rates. This is how UNESCO reports in its document on the adverse consequences of school closures caused by the COVID-19 pandemic [12] and other previous research [18] that have analyzed the achievement of students who suffered a school closure.

In addition to all these elements, the pandemic has revealed a series of consequences that must be taken into account at the educational management level. A recent report [19] highlighted several problems facing the educational system. The pandemic has forced the immediate transfer of teaching to the online modality without time to carry out authentic planning and a modification of the curriculum design to adapt it to the online modality, which has led to "remote teaching of emergency" [20]. On this matter, these researchers highlight that teachers and administrators must take into account that students may not be able to attend online training immediately, resulting in an untimely delivery of assignments. For this reason, flexibility with deadlines for assignments within courses, course policies, and institutional policies should be considered. An example of this is the action plan carried out by the United States Department of Education [16] that has relaxed some of the requirements and policies against COVID-19 such as content adaptation, flexibility in evaluation criteria, or the adaptation of methodological elements to online teaching. In this crisis situation, it is necessary to carry out a deep reflection on the evaluation and promotion processes of the students and take into account the collateral effects that a drastic increase in the number of students who would have to repeat the subjects would cause.

\section{Working during COVID-19: Training Needs of Teachers in the Face of a Paradigm Shift}

Faced with such exceptional circumstances caused by the pandemic as a result of COVID-19, in a context in which schools have closed their doors in 185 countries and government administrations have ordered the transition to the tele-training of students, it has manifested the need to train teaching staff in the use of different technological tools, in order to adapt the different elements of the curriculum to the new context of a pandemic. We are facing a change in the educational paradigm in which online training through ICT has ceased to be an option in the teaching methodology and has become a necessity in these times of pandemic in order to continue with the student learning process.

The World Education Monitoring Report [21] concludes that only $40 \%$ of adults in upper-middle-income countries are able to send an email with an attachment. Recent research 
shows deficits in relation to digital competence and low-medium teacher training, although teaching staff showed a positive attitude toward ICT [22]

On the other hand, there is also another essential question so that the professional work of teachers can be adapted to online education. It is the fact of how prepared schools are to face these changes toward virtual teaching. On this matter, the 2018 PISA report reported the results of a survey carried out on the management of educational centers. The survey reflected that between $30 \%$ and $80 \%$ had the professional skills and resources to learn how to integrate digital devices into teaching. The countries that stood out the most were fundamentally South Korea, the Nordic countries, Canada, and the United States, with proportions between 70 and $80 \%$ [19].

The sudden metamorphosis of teaching activity from the face-to-face model to the online modality reveals the existence of three gaps [23]: the access gap (having or not having access to connection and technological devices); the use gap (time of use and its quality); and the gap in teacher skills, availability of resources, and adaptation of online platforms to support teaching). This digital gap makes the distances between families with more and less resources ever greater, as is occurring during the period of confinement [19].

Technologies and, particularly in recent years, the Internet, have influenced the way of learning, working, and socializing by modifying the concept of distance and time in access to information. This reality has required the development of new personal, social, and professional skills. In this sense, transforming information into knowledge requires reasoning skills to organize information, relate it, analyze it, synthesize it, and make inferences and deductions of different levels of complexity [24].

Another study [25] analyzed the experiences and methodological conceptions of teachers in primary education on collaborative learning with WebQuests and MOOCs (Massive Online Open Courses) in the curricular area of Social Sciences. The results obtained demonstrate the educational need to transfer and integrate, in an operational and functional way, the progress and generalization of Information and Communication Technologies in teacher training curricula. Specifically, the research reported low or very low values in the teaching staff in relation to the knowledge of the technological resources along the line of other investigations $[26,27]$.

On the other hand, several investigations have pointed to a series of factors that are present when teachers face the inclusion of the technologies and apply them in their teaching work. These are [28]:

- The high motivation that teachers present for increasing their competence in the use of technologies.

- A perception of poor knowledge in the use of technologies.

- Despite the large number of training activities, the competence in the use of technologies has not improved sufficiently.

- The teacher has the perception that their competence is greater in tools denominated as traditional than in the management of the technologies.

On the other hand, teaching staff, as a teaching worker, must also adapt their work methodology, which implies carrying out a training process that serves as a guide to assimilate the context caused by the coronavirus crisis. In this sense, it is necessary to approach teacher training in the use of ICT in two lines of work: firstly, the acquisition of different levels of competence of teachers in ICT and, on the other hand, the improvement in a series of pedagogical, social, ethical, legal, technical, and school and school management [28].

As for the first proposal, we assumed the line of Segura, Candioti, and Medina [29], who exposed the different levels of training that teachers can achieve with respect to their competence of the use of ICT. These are: basic, referring to those competencies that are necessary for the performance to be developed; advanced, referring to the competences necessary for a work with greater autonomy and creativity; and specific, referring to the level of competence required for the performance of specific teaching positions and that requires mastering specific applications.

Regarding the second proposal in teacher training in the use of ICTs, [28] established the following dimensions to be addressed in teacher training: instrumental, acquiring minimal competition in the use 
of ICT; to master of the own language of the ICT to carry out the codification and decoding of messages; curricular, any medium is susceptible to be included in the teaching program; pragmatic, to know how to differentiate the purpose of each medium with respect to the proposed objectives; psychological, to recognize that ICT can develop specific cognitive skills; a producer and designer to facilitate the teacher to achieve levels of competence that will make them a designer of educational applications; selection and evaluation oriented toward the acquisition of selection and evaluation capacity; critical to contribute to a realistic perception of the use of ICT; organizational, which contributes to reach the objectives set; attitudinal, to foster positive attitudes in the use of ICT by students; researcher, to make teachers aware that this not only applies to the technologies in the classroom, but also can be an innovative agent; and communicative, to be able to create various communication scenarios.

\section{The Optimization of the Use of Information and Communication Technologies (ICT) under the Focus of the Contributions of Neuroeducation}

Neurosciences are developing investigations focused on the neural bases of learning, memory, emotions, and different functions of the brain, the results of which have high applicability in the field of learning [30]. This is because the foundation of neuroeducation is a concept called brain plasticity, which is the brain's ability to physically change to adapt to stimuli and habits in ways that are useful to the individual. In this sense, learning and emotion are very close. Thus, in meaningful learning, relevant information is linked with sensations and feelings linked to pleasure that make us internalize them earlier. In this way, neuroeducation emphasizes the need to use an emotional approach both in classrooms and in any educational context. According to these authors, neuroeducation is a new discipline that relies on the contributions of neuroscience, cognitive psychology, and education sciences to create a better understanding of how a human being is capable of learning and how this information can be applied to create teaching methods as well as plan more effective study and educational policies. Neuroeducation deals with the study of the different stimuli that the student perceives in the teaching-learning process, through the senses, to give rise to meaningful learning. In short, the use of ICT from a neuroeducational approach would allow greater profitability in terms of learning in the current context of the crisis caused by the coronavirus, in which online training is proving to be a feasible solution in the context of the closure of educational centers. The integration of ICT and the contributions of neuroeducation, neuroscience, and educational neuro-technology help the student to build their own learning strategies through new paradigms that facilitate learning processes in the context of online teaching [31]. This is because the significant learning processes are based on brain operations, the results of which change the circuits of the brain. Neuroeducation deals precisely with the study of the optimization of learning based on brain development. This interdisciplinary approach between ICT and neuroeducation facilitates meaningful learning by creating interactive learning spaces in which the presentation of content through the innovative possibilities offered by ICT in online teaching offers teacher-student interactivity that arouses the interest of the students. This situation causes the connection between neurons or the neurotransmission process, that is, the transmission of information from one neuron to another neuron, to obtain effective results when explaining the new content.

In the previous bibliography, experiences could be found that were focused on the symbiosis of neuroeducation and the application of ICT. This was the case of the use of augmented reality as a recreational pedagogical tool to optimize significant learning processes based on stimulation linked to emotions and sensory stimulation [32]. This tool produces a series of chemical substances that stimulate the act of learning. This research concluded that the use of augmented reality stimulated the senses, increasing the levels of attention in students. Likewise, it was reported that this technological tool improved the transmission of information in an interactive and playful way. With this, the students enriched their learning experiences based on emotional empathy.

Along the same lines, there is research aimed at interconnecting the disciplines of education-ICT-neuroscience through learning games [33]. These authors developed a design-based 
research approach to the development of learning technology supported by neuroscience. Specifically, the study proposal allowed teachers to carry out teaching using a game-based approach and its neuroscientific implications. For these authors, the brain's reward system is based on the fact that the brain is motivated through stimuli such as winning points in a game. This activity involves the absorption of the neurotransmitter called dopamine in the midbrain regions and this would imply greater motivation for the activity in question. This reward system has provided a new understanding of the educational potential of learning games and the cognitive and neural processes underlying the neural process. To do this, a multidisciplinary team designed a computer application that took into account neuroeducational theory that explains the behavior of the human brain when faced with stimuli such as play, the teachers' knowledge based on practical experiences in the classroom, and the design and use of ICT. Therefore, the conclusions derived from this study were assumed. It is proposed to include learning activities based on games through the use of ICT and that responds to the information provided by the neurosciences such as the brain stimulation due to these types of activities aimed at meaningful learning.

In relation to the learning environment and motivation of students, Barattucci and Bocciolesi [34] analyzed the use of phenomenology in the Student Learning Perspective (SLP), affirming that students' perceptions of the learning environment, in light of their motivations and expectations, determine how situational factors influence approaches to learning outcomes. This approach provides not only a contextualized interpretation of learning phenomena, but also offers relevant information for the development of a teaching strategy that can improve the learning experience of students.

Along this line, Barattucci [35] carried out a study in which he stated that there were no systemic reference models that consider environmental variables in online learning and offers an integrated model to evaluate the contribution of different variables in predicting the performance of distance learning students. In the model proposed by the author, variables such as perception of the physical learning environment, perception of course design, and personal variables are established as predictors of student performance.

Regarding the high motivation of teachers to increase their competence in the use of technologies, the study carried out by Santisi, Magnano, Platania, and Ramaci [36] on the transition from university to work considered that some psychological resources and skills were involved specifically to achieve further professional training. The authors concluded that academic satisfaction had a direct effect on confidence in the process of transition to the professional field and is a predictor of the professional identity of preparation for professional transitions. Consequently, for these authors, increasing motivation influences the development of knowledge and skills.

On the other hand, the use of ICT also involves constructivist-based learning since its use gives students control over their own learning through self-regulatory mechanisms that are set in motion under precise stimulation [37]. When significant learning is carried out through various brain operations, modifications occur at the level of the brain circuits. In this way, neuroeducation provides the necessary tools for the student to optimize the brain's potential more effectively.

Despite the fact that ICTs are constantly being updated, most of the traditional platforms are oriented to content, content administration, and the application of teacher-centered methodologies [38]. Therefore, a review of online learning is necessary that is capable of combining technological advances and the principles of neuroeducation focused on students, which can stimulate motivational processes toward meaningful learning.

\section{Conclusions}

The pandemic caused by the COVID-19 disease is leaving devastating consequences in society from a social, health, political, educational, and labor point of view. In the educational field, a paradigm shift is going on that goes beyond the merely methodological. The fact that different educational administrations have had to carry out a transfer of the educational system from face-to-face teaching to online teaching at a speed of real urgency is causing the use of ICT to have gone from being one 
more methodological resource to a necessary solution so that the teaching and learning process is not interrupted, thus avoiding the collapse of educational systems worldwide. This has been an educational, but also a health measure since the closure of schools and the adoption of online education would help stop the spread of the pandemic [39].

For this reason, the transformations that are taking place are affecting the teaching profession itself, while education professionals must adapt to the new situation. The teacher's role in the effective use of ICT tools in the teaching-learning process after the COVID-19 crisis is essential [36], For this, teachers have to have training that leads to them assimilating the pedagogical uses of ICT. In this way, the generation of new learning styles would be facilitated. On the other hand, for the learning to be more effective, a proposal that has been put forward is to lean on the discipline of neuroeducation through the management of emotions and at the same time, optimize the academic performance of students and work of teaching professionals. In this way, knowledge of the brain provides essential information that can facilitate meaningful learning through emotions. In fact, previous research [40] has shown the activation of cerebral regions of the right hemisphere such as the lingual gyrus, the posterior hippocampal gyrus, the anterior hippocampal gyrus, and the fusiform gyrus when faced with positive emotional stimuli; these are areas whose neurocircuits are involved in the facilitation of memory processes. This directly impacts the need of the educational system to generate school climates that promote respect and positive emotions, in order to facilitate learning processes.

Along the line of other authors [19], a series of measures were assumed that must precede the proposal presented such as the provision of material resources (especially technological devices) and human resources as well as the reformulation of the elements of curricula including evaluation processes.

Faced with this pandemic situation, online teaching, as has been described throughout the article, is becoming a solution in order to continue with the development of academic curricula. It should be noted that this type of teaching modality has its pros and cons that must be paid attention to. As advantages, the flexibility of schedules and spaces stands out, but collaborative work with participation and interaction through forums, chat, and other tools requires great discipline and organization as well as a high degree of individualized follow-up by the teacher. As cons, the socialization factor can be highlighted due to the lack of social interaction with classmates and teachers, the lack of technological knowledge necessary to face this type of teaching, the quality of technological means and tools, and a higher performance and dedication of time in students with the continuous delivery of activities, but also in the teachers with the resolution of doubts and correction of works permanently to control the learning process of the students.

These are measures that fall not only on political leaders or teachers and school leaders, but also on families themselves. This shows that, like the fight against COVID-19, this is a shared responsibility.

Author Contributions: The authors contributed equally to this work. All authors have read and agreed to the published version of the manuscript.

Funding: This research received no external funding.

Conflicts of Interest: The authors declare no conflicts of interest.

\section{References}

1. Zhang, W.; Wang, Y.; Yang, L.; Wang, C. Suspending Classes Without Stopping Learning: China's Education Emergency Management Policy in the COVID-19 Outbreak. J. Risk Financ. Manag. 2020, 13, 55. [CrossRef]

2. CSIF. Un 93\% de Docentes Sufre Desgaste Emocional y Estrés Por El Confinamiento. 2020. Available online: https://www.csif.es/contenido/nacional/general/297367 (accessed on 16 May 2020).

3. Fernández-Cruz, F.J.; Fernández-Díaz, M.J. Los Docentes de La Generación Z y Sus Competencias Digitales. Comunicar 2016, 24, 97-105. [CrossRef] 
4. Cabrera, A.F.; Cruz, C.S.L.; Sánchez, S.P. Análisis de La Competencia Digital Docente: Factor Clave En El Desempeño de Pedagogías Activas Con Realidad Aumentada Analysis of the Digital Teaching Competence: Key Factor in the Performance of Active Pedagogies with Augmented Reality Introducción. Reice Rev. Iberoam. Sobre Calid. Efic. Cambio Educ. 2019, 17, 27-42.

5. Amhag, L.; Hellström, L.; Stigmar, M. Teacher Educators' Use of Digital Tools and Needs for Digital Competence in Higher Education. J. Digit. Learn. Teach. Educ. 2019, 35, 203-220. [CrossRef]

6. Colás-Bravo, P.; Conde Jiménez, J.; Reyes de Cózar, S. El Desarrollo de La Competencia Digital Docente Desde Un Enfoque Sociocultural. Comunicar 2019, 27, 21-32. Available online: https://www.revistacomunicar. com/ojs/index.php/comunicar/article/view/C61-2019-02 (accessed on 25 May 2020).

7. Dong, E.; Hongru, D.; Lauren, G. COVID-19 in Real Time. Lancet Infect. Dis. 2020, 3099, 19-20. [CrossRef]

8. COVID-19 Coronavirus Global Cases. n.d. Available online: https://www.worldometers.info/ (accessed on 13 May 2020).

9. Markel, H.; Lipman, H.B.; Navarro, J.A.; Sloan, A.; Michalsen, J.R.; Stern, A.M.; Cetron, M.S. Non Pharmaceutical Interventions Implemented by US Cities During the 1918-1919 Influenza Pandemic. AMA 2015, 298, 7-27.

10. Prem, K.; Liu, Y.; Russell, T.W.; Kucharski, A.J.; Eggo, R.M.; Davies, N.; Flasche, S.; Clifford, S.; Pearson, C.A.; Munday, J.D.; et al. The Effect of Control Strategies to Reduce Social Mixing on Outcomes of the COVID-19 Epidemic in Wuhan, China: A Modelling Study. Lancet Public Health 2020, 5, 261-270. [CrossRef]

11. Downie, B. Effects of School Closure on Incidence of Pandemic Influenza in Alberta, Canada. Thorax 2012, 67, 949. [CrossRef]

12. UNESCO. Adverse Consequences of School Closures. 2020. Available online: https://en.unesco.org/covid19 (accessed on 30 May 2020).

13. Sanz, I.; Sáinz, J.; Capilla, A. Efectos de La Crisis Del Coronavirus Sobre La Educación-Magisnet; Organización de Estados Iberoamericanos Para La Educación, La Ciencia y La Cultura: Madrid, Spain, 2020; Available online: https://www.oei.es/Ciencia/Noticia/oei-analiza-como-afectara-el-cierre-colegios-coronavirus (accessed on 25 May 2020).

14. Wößmann, L. Schooling Resources, Educational Institutions and Student Performance: The International Evidence. Oxf. Bull. Econ. Stat. 2003, 65, 117-170. [CrossRef]

15. Furió, D.; Juan, M.C.; Seguí, I.; Vivó, R. Mobile Learning vs. Traditional Classroom Lessons: A Comparative Study. J. Comput. Assist. Learn. 2015, 31, 189-201. [CrossRef]

16. Means, B.; Toyama, Y.; Murphy, R.; Bakia, M.; Jones, K. Evaluation of Evidence-Based Practices in Online Learning: A Meta-Analysis and Review of Online Learning Studies. In Learning Unbound: Select Research and Analyses of Distance Education and Online Learning; Department of Education, US: Washington, DC, USA, 2012. Available online: https://www2.ed.gov/rschstat/eval/tech/evidence-based-practices/finalreport.pdf (accessed on 30 May 2020).

17. Jaume, D.; Willén, A. The Long-Run Effects of Teacher Strikes: Evidence from Argentina. J. Labor Econ. 2019, 37, 1097-1139. [CrossRef]

18. Zubillaga, A.; Cortazar, L. COVID-19 Y EDUCACIÓN: Problemas, Respuestas y Escenarios; COTEC: Madrid, Spain, 2020.

19. Hodges, C.; Moore, S.; Lockee, B.; Trust, T.; Bond, A. The Difference between Emergency Remote Teaching and Online Learning; EDUCAUSE Review: Louisville, CO, USA, 2020. Available online: https://er.educause. edu/articles/2020/3/the-difference-between-emergency-remote-teaching-and-online-learning (accessed on 3 June 2020).

20. UNESCO. Migration, Displacement \& Education: Building Bridges, Not Walls. 2019. Available online: https://en.unesco.org/gem-report/report/2019/migration (accessed on 3 June 2020).

21. Muñoz-Pérez, E.; Cubo-Delgado, S. Digital Competence, Special Education Teachers'training and Attitude towards the ICT (Information and Communication Technologies). Profesorado 2019, 23. [CrossRef]

22. Fernández-Enguita, M.; Vázquez-Cupeiro, S. La Larga y Compleja Marcha DEL BIC AL BIT: El Acceso a Los Recursos Digitales En La Educación; Ariel: Barcelona, Spain, 2017.

23. Miralles-Martínez, P.; Gómez-Carrasco, C.J.; Sánchez-Ibañez, R. Ask Me Questions and I Will Tell You What They Assess and Teach. An Analysis of Social Sciences Exams in the 5th and 6th Grade of Primary School. Aula Abierta 2014, 42, 83-89. [CrossRef] 
24. Ortega-Sánchez, D.; Gómez-Trigueros, I.M. Massive Open Online Courses in the Initial Training of Social Science Teachers: Experiences, Methodological Conceptions, and Technological Use for Sustainable Development. Sustainability 2019, 11, 578. [CrossRef]

25. Ramos, L.E. Utilización de Las Webquest Como Recurso Educativo En Educacion Física. Quad. Digit. Rev. Nuevas Tecnol. Soc. 2009, 59. Available online: http://quadernsdigitals.net/datos_web/hemeroteca/r_1/nr_806/ a_10869/10869.pdf (accessed on 3 June 2020).

26. Gómez-Trigueros, I.M.; Sánchez-Ortega, D. Los MOOC En La Didáctica de La Geografía: Aplicaciones En La Formación Inicial Del Profesorado de Primaria. In Nuevas Perspectivas Conceptuales y Metodológicas Para La Educación Geográfica; Martínez-Medina, R., Ed.; University of Cordoba: Córdoba, Spain, 2014; pp. 229-244.

27. Cabero, J. La Formación Del Profesorado Para El Manejo de Las TIC En Los Procesos de Enseñanza/Aprendizaje. In Incorporación de Las TIC En Los Programas Académicos de Las Universidades Estatales Costarricenses; Martínez, F., Ed.; Diego Marín: Murcia, Spain, 2008; pp. 55-68.

28. Cabaro, J.; Marín, V. Miradas Sobre La Formación Del Profesorado En TIC. Enl@Ce Rev. Venez. De Inf. Tecnol. Y Conoc. 2014, 11, 11-24.

29. Segura, M.; Candioti, C.; Medina, J. Las TIC En La Educación: Panorama Internacional y Situación Española; Fundación Santillana: Madrid, Spain, 2007.

30. Espino-Díaz, L.; Alvarez-Castillo, J.-L.; Gonzalez-Gonzalez, H.; Hernandez-Lloret, C.-M.; Caminero-Fermandez-Caminero, G. Creating Interactive Learning Environments through the Use of Information and Communication Technologies Applied to Learning of Social Values: An Approach from Neuro-Education. Soc. Sci. 2020, 9, 72. [CrossRef]

31. Mendoza, L.-R.; Moya, E. TIC y Neuroeducación Como Recurso de Innovación En El Proceso de Enseñanza y Aprendizaje ICT and Neuroeducation as a Resource of Innovation in the Process of Teaching and Learning. Rehuso Rev. de Cienc. Hum. Y Soc. 2020, 5, 85-96.

32. Fernández-García, C.E. Neuroeducación En Entornos de Realidad Aumentada. Temát. Psicol. 2017, 13, 43-50. [CrossRef]

33. Howard-Jones, P.; Holmes, W.; Demetriou, S.; Jones, C.; Tanimoto, E.; Morgan, O.; Perkins, D.; Davies, N. Neuroeducational Research in the Design and Use of a Learning Technology. Learn. Media Technol. 2015, 40, 227-246. [CrossRef]

34. Barattucci, M.; Bocciolesi, E. Phenomenography in the Student Learning Perspective: A Review of Studies in Academic Contexts. Encyclopaideia 2018, 22, 21-34. [CrossRef]

35. Barattucci, M. Predicting Learning Outcomes in Distance Learning Universities: Perspectives from an Integrated Model. In Communications in Computer and Information Science; Daniel Burgos, Marta Cimitile, Pietro Ducange, Riccardo Pecori, Pietro Picerno, Paolo Raviolo, and Christian M Stracke; Springer: Berlin/Heidelberg, Germany, 2019; pp. 30-40. [CrossRef]

36. Santisi, G.; Magnano, P.; Platania, S.; Ramaci, T. Psychological Resources, Satisfaction, and Career Identity in the Work Transition: An Outlook on Sicilian College Students. Psychol. Res. Behav. Manag. 2018, 11, 187-195. [CrossRef] [PubMed]

37. Calle-alonso, F.; Cuenca-guevara, A.; Mata-Lara, D.; Sánchez-gómez, J.M.; Vega-rodríguez, M.A.; Pérez Sánchez, C.J. NeuroK: A Collaborative e-Learning Platform Based on Pedagogical Principles from Neuroscience. In Proceedings of the 9th International Conference on Computer Supported Education; Csedu: Porto, Portugal, 2017; pp. 550-555. [CrossRef]

38. CAF. El Estado de La Digitalización de América Latina Frente a La Pandemia Del COVID-19; CAF: Caracas, Venezuela, 2020.

39. Naresh, R. Education after COVID-19 Crisis Based on ICT Tools Purakala. Ugc Care J. 2020, 31, 464-468.

40. Román, F.; Victoria, P. La Neurociencia Aplicada a La Educación: Aportes, Desafíos y Oportunidades En América Latina. Neurocienc. Y Educ. Infant. 2018, 7, 88-93.

(C) 2020 by the authors. Licensee MDPI, Basel, Switzerland. This article is an open access article distributed under the terms and conditions of the Creative Commons Attribution (CC BY) license (http://creativecommons.org/licenses/by/4.0/). 